\title{
Measurement Science and Technology at 2015
}

\section{Editorial}

As a New Year starts it is my pleasure once again to thank the global measurement community for its support for Measurement Science and Technology. With the help of our authors, reviewers, Editorial Board and staff at IOP Publishing the journal continues to go from strength to strength. In 2014 the average review time from receipt to acceptance was down to $107.5 \mathrm{~d}$, with record-breaking downloads every month between May and September. As I write, the journal looks to be on track for over 400000 downloads for the year. With these statistical improvements has also come an improvement in quality, with the journal awarding a record number of five Outstanding Paper Awards in 2014 for papers published in 2013. Awards were presented in the areas of Fluid Mechanics, Measurement Science, Precision Measurement, Sensors and Sensing Systems, and Optical and Laser-based Techniques. In my interview for the journal's 90th Anniversary in 2013 I highlighted a number of exciting frontiers of measurement, including the breaking of the diffraction limit that has led to single molecule detection. I was particularly pleased to see the award of the 2014 Nobel Prize for Chemistry to Eric Betzig, Stefan W Hell and William E Moerner for their pioneering work in this area. The Nobel Prize for Physics also went to a breakthrough in optics with the Award to Isamu Akasaki, Hiroshi Amano and Shuji Nakamura for the invention of efficient blue light-emitting diodes. Both these prizes continue to feed through to measurement science across the disciplines, and on behalf of the journal I am delighted to give our heartiest congratulations to the winners.

Topical Reviews in particular continue to attract wide interest. They serve as very useful updates for both newcomers to a field and long-standing practitioners. In 2014 the journal published reviews on the viscosity of metals [1], affinity biosensors [2], quantum cascade lasers [3], energy harvesting in buildings [4] and for implantable medical devices and biomedical sensors [5], many of these diverse topics again illustrating the commonality that defines measurement science across the disciplines. As we look ahead, the coming year 
will bring Topical Reviews on spray measurement technology, spectroscopic probing of luminescent materials and diagnostics for characterization of plasma actuators. There will also be a Perspective by Editorial Board members Kara Peters and Ralph Tatam in celebration of 2015 as the International Year of Light. Also, Special Issues and Features planned this year include expanded contributions from the 16th International Symposium on Flow Visualisation (ISFV16), a special IMEKO session on metrology for particle accelerators, and MacroScale 2014.

For many years our Topical Reviews have been ably edited by Richard Dewhurst of the University of Manchester. Richard retired from the Editorial Board at the end 2014. If you have not yet read it, Richard's historical review [6] of the journal from its birth as the world's first measurement journal, and first research journal produced by the Institute of Physics, is particularly interesting. We wish Richard well, thank him for his many contributions to the journal's development over two decades and welcome Fulvio Scarano of the University of Delft in his role as the new Topical Reviews Editor.

All that remains for me is to welcome in a New Year and wish you all joy and success in 2015. David J S Birch Editor-in-Chief, University of Strathclyde, Glasgow, UK E-mail: djs.birch@strath.ac.uk

\section{References}

[1] Cheng J, Groebner J, Hort N, Kainer K U and Schmid-Fetzer R 2014 Measurement and calculation of the viscosity of metals-a review of the current status and developing trends Meas. Sci. Technol. 25062001

[2] Arugula M A and Simonian A 2014 Novel trends in affinity biosensors: current challenges and perspectives Meas. Sci. Technol. 25032001

[3] Bartalini S, Vitiello M S and De Natale P 2014 Quantum cascade lasers: a versatile source for precise measurements in the mid/far-infrared range Meas. Sci. Technol. 25012001 
[4] Matiko J W, Grabham N J, Beeby S P and Tudor M J 2014 Review of the application of energy harvesting in buildings Meas. Sci. Technol. 25012002

[5] Cadei A, Dionisi A, Sardini E and Serpelloni M 2014 Kinetic and thermal energy harvesters for implantable medical devices and biomedical autonomous sensors Meas. Sci. Technol. 25012003

[6] Dewhurst R J 2013 Measurement Science and Technology: a historical perspective Meas. Sci. Technol. 24012006

Meas. Sci. Technol. 26 (2015) 010201 